\title{
Desvelando afinidades através das diferenças: saberes e estéticas pós/ descoloniais
}

Leila Assumpção Harris

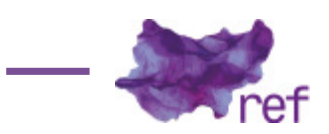

Resumo: Sob o viés do feminismo multicultural, os conceitos de relacionalidade, de posicionamento dos discursos e das interseccionalidades de opressões são instrumentais para um melhor entendimento das múltiplas perspectivas que norteiam as práticas feministas atuais, ancoradas em saberes e estéticas pós e descoloniais. Nosso objetivo é colocar em pauta as práticas e estéticas políticas adotadas por mulheres de lugares geográficos e sociais bastante diversos. A produção artística que desenvolvem através de linguagens e narrativas variadas promove possibilidades de fomentar poéticas de resistência e descolonização de gênero que desafiam nossa compreensão tradicional sobre o estético, o político e o epistemológico.

Palavras-chave: feminismo multicultural; relacionalidade; posicionamento de discursos; interseccionalidades; práticas políticas e estéticas

Unveiling Affinities Through Differences: Post/Decolonial Knowledges and Aesthetics Abstract: Under the bias of multicultural feminism, the concepts of relationality, discourse positioning and intersectionalities of oppressions are instrumental for a better understanding of the multiple perspectives that inform current feminist practices, anchored in post/decolonial knowledges and aesthetics. Our discussion aims to address political practices and aesthetics adopted by women from very diverse social and geographic places. The artistic/cultural production that is developed through varied languages and narratives promotes possibilities to foster poetics of gender resistance and decolonization that challenge our traditional understanding of the aesthetic, political, and epistemological.

Keywords: multicultural feminism, relationality; discourse positioning; intersectionalities; political practices and aesthetics

Feminismo é o quê? Uma gangue? Facção? Eu não quero fazer parte de uma gangue... Quero fazer parte de
um mundo melhor, um mundo que respeite e iguale nos direitos não só das mulheres mas a todos: negros,
deficientes, gays, obesos (Mc CAROL, 2016). ${ }^{\top}$

\section{0 feminismo multicultural: diferenças e afinidades}

Os comentários sobre feminismo contidos nas epígrafes foram feitos por duas mulheres de lugares geográficos e sociais totalmente diversos. No entanto, a funkeira brasileira Mc Carol e a escritora nigeriana Chimamanda Adichie concordam que feminismo não deve implicar

${ }^{1}$ http://www.meio22.com.br/2016/02/o-feminismo-periferico.html?m=1. 
hierarquização e discriminação. A própria iniciativa de explicar o que entendem por feminismo aponta a natureza controversa do termo e a recorrência do procedimento discursivo que, de acordo com Simone Pereira SCHMIDT (2016), "induz mulheres a dissociarem suas práticas daquilo que se entende por feminismo" (p. 15). E o que se entende por feminismo varia de acordo com os locais sociais, históricos e geográficos. Na realidade, faz mais sentido falar de feminismos, usando o plural, englobando o feminismo europeu, a chamada segunda onda do feminismo estadunidense, assim como feminismos produzidos entre grupos minoritários, feminismos "construídos em suas diferenças" (SCHMIDT, 2016, p. 16).

Ella SHOHAT (2004) ressalta a importância da diferença para mulheres escritoras de cor e do terceiro mundo, mas deixa claro que sua abordagem não envolve estabelecer "ideias essencialistas sobre diferenças culturais [...] mas sim examinar posicionamentos diferentes em relação às histórias de poder, especialmente dentro do colonialismo" (p. 26). Propõe então a adoção de um feminismo multicultural: "uma prática situada, na qual histórias e comunidades estão mutuamente coimplicadas e constitutivamente relacionadas, abertas a uma iluminação mútua" (SHOHAT, 2004, p. 26). A proposta de Shohat nos remete à discussão sobre discursos identitários elaborada por Susan Stanford FRIEDMAN (1998) em Mappings: Feminism and the Cultural Geographies of Encounter, onde a crítica aponta a necessidade de ir "além do gênero", não no sentido de deixar o conceito para trás, mas de incorporar outros "constituintes identitários", de considerar o gênero a partir de uma perspectiva "espacializada" ou "locacional", ou seja, a partir de uma nova "geografia identitária" (p. 17-18). De acordo com Friedman (1998), qualquer identidade pode ser lida como um local onde "eixos diferentes tais como raça, etnia, gênero, religião, classe, sexualidade, idade" (p. 109), entre outros, se interseccionam. Kimberlé CRENSHAW (2002) argumenta que as diversas categorias operam comumente como "eixos de subordinação" (p. 177), que podem interagir e atuar como forças simultâneas de opressão. A simultaneidade destas forças não significa, no entanto, que elas atuem de maneira uniforme em contextos diversos.

Os conceitos de relacionalidade, de posicionamento dos discursos e das interseccionalidades de opressões são instrumentais para um melhor entendimento das múltiplas perspectivas que informam práticas feministas atuais. Ancoradas em saberes e estéticas pós e descoloniais e adotadas por mulheres de lugares geográficos e sociais diversos, tais práticas têm seus alicerces nas diferenças, mas também nas semelhanças. Este ensaio é um desenvolvimento do trabalho apresentado no Simpósio Temático do Fazendo Gênero 1 1, "Feminismos Transnacionais: saberes e estéticas pós/descoloniais", coordenado por Ana Gabriela Macedo e Simone Schmidt. Um dos nortes da minha apresentação veio do resumo do simpósio, mais especificamente da passagem:

Podemos afirmar que a grande contribuição feminista ao pensamento contemporâneo tem sido, por um lado, a desconstrução dos paradigmas etnocêntricos do sistema moderno-colonialpatriarcal em que fomos formados, e, por outro lado, a proposição de sistemas outros de saberpoder que descortinam possibilidades de novos agenciamentos políticos e de construção de epistemologias heterodoxas e não hegemônicas (Ana Gabriela MACEDO \& SCHMIDT, 2017).

\section{Saberes e estéticas pós e descoloniais}

O evento, realizado na Universidade Federal da Bahia em 25 de julho de 2017 em celebração ao Dia Nacional de Teresa de Benguela (líder do maior grupo de resistência na Capitania de Mato Grosso no século XVIII) e da Mulher Negra Latino-Americana e Caribenha, ressaltou a importância de descolonizar o feminismo negro no Brasil, desestruturando os controles que atuam sobre $25 \%$ da população brasileira, em especial as mulheres negras. A apresentação do Slam das Minas na abertura do evento colocou em foco tanto "a solidão da mulher preta" quanto sua capacidade de resistência, dramatizando um dos pontos da palestra proferida na ocasião por Angela Davis: o caráter coletivo do feminismo negro. ${ }^{2}$ A escritora e ativista política expressou sua convicção de que o movimento social liderado por mulheres negras é o mais importante na atualidade brasileira. Deixa claro, no entanto, que ao falar da mulher negra não se limita às perspectivas de gênero e raça - reconhecendo assim o papel das interseccionalidades - nem propõe uma abordagem separatista. Observa também que as mulheres negras se engajam com frequência na luta de outros grupos oprimidos.

As redes de poder que influenciam o trânsito de ideias e conhecimento entre os hemisférios norte-sul é outro ponto abordado na palestra de grande relevância para a presente discussão. Davis comenta que o feminismo negro estadunidense é considerado como o mais avançado e que há muitas figuras proeminentes responsaveis pelo seu desenvolvimento naquele país, mas alerta contra uma postura colonialista e argumenta que ideias circulam com muito mais facilidade

\footnotetext{
${ }^{2}$ Ver também SOUZA, Raquel Luciana de (trad. e int.). "Leia transcrição na íntegra da fala de Ângela Davis na Universidade Federal da Bahia". Revista Fórum, 18/07/2017. Disponível em: https://www.revistaforum.com.br/leiatranscricao-na-integra-da-fala-de-angela-davis-na-universidade-federal-da-bahia/.
} 
a partir dos Estados Unidos do que a partir do Brasil, por exemplo. Observa que suas várias viagens ao Brasil têm Ihe trazido novas perspectivas e mantém que as feministas estadunidenses têm muito a aprender com a longa história de luta feminista negra no Brasil. Propõe, então, a "solidariedade para além das fronteiras nacionais" e ressalta as profundas conexões entre o feminismo radical negro descolonial e outros feminismos ainda que reconheça as contradições/ diferenças existentes.

O potencial de transformação que nasce da criatividade e se manifesta através de linguagens diversas contribui para promover a descolonialidade de gênero. Inspirada pela mensagem de Davis, atravesso o eixo norte-sul para abordar a produção artística/cultural de mulheres situadas em lugares geográficos e sociais totalmente diferentes, contemplando afinidades e diferenças.

Chimamanda Ngozi Adichie, que nasceu na Nigéria, migrou para os Estados Unidos e agora divide seu tempo entre os dois países. É autora de três romances e uma coletânea de contos. Em entrevista à Daria Tunca (2005), Adichie comenta o viés político de suas obras que já receberam inúmeros prêmios e foram traduzidas para mais de trinta idiomas.

Não acredito que todo escritor deva exercer um papel político, mas penso que eu, como uma pessoa que escreve ficção realista sobre a África, tenho quase automaticamente um papel políico. Em um lugar onde recursos escassos tornam-se mais escassos por meios artificiais, a vida é sempre políica [...].

Em suas obras ficcionais o viés político se faz presente especialmente, mas não exclusivamente, através dos temas abordados. Em Americanah (2013), o mais recente e premiado romance de Adichie, Ifemelu, a protagonista, também nigeriana, que reside nos Estados Unidos por treze anos, mantém um blog (Raceteenth or Various Observations About American Blacks (Those Formerly Known as Negroes) by a Non-American Black) onde publica comentários sobre um tópico que, de acordo com ela, os americanos preferem evitar: raça. Após retornar à Nigéria, Ifemelu começa outro blog, The Small Redemptions of Lagos. Em entrevista a Michel Martin (2014), Adichie declarou que fez de Ifemelu uma blogueira pois queria incluir comentário social em seu romance por meio de formas diferentes daquelas que havia utilizado em suas outras obras de ficção. A crítica Serena GUARRACINO (2014) discorre sobre o espaço importante que os blogs ocupam no romance e argumenta que, conforme as postagens se tornam mais frequentes, "a distinção entre os blogs e a ficção esmaece: Ifemelu utiliza o blog como uma forma híbrida que combina histórias, reportagem e valor emocional". A crítica esclarece:

Na realidade, à medida que o romance progride, o comentário social transita constantemente do blog para o romance e vice-versa, contaminando a ficção com o ímpeto de elaborar ideias expressas através do blog mas ao mesmo tempo permeando as postagens com emaranhados emocionais associados à escrita criativa (p. 2).

Em Colonial and Postcolonial Literature, Elleke BOEHMER (2005) descreve em linhas gerais o/a escritor/a pós-colonial do século XXI:

Ex-colonial de nascença, 'terceiro-mundista' em interesses culturais, cosmopolita em quase todos os outros sentidos, ele ou ela trabalha na esfera de uma metrópole ocidental, ao mesmo tempo em que mantém conexões temáticas e/ou políticas com suas raízes nacionais, étnicas ou regionais (p. 227).

Ainda que seja crucial não cair em categorias essencialistas, percebemos que Chimamanda Adichie pode ser incluída nesta descrição. Boehmer evoca Homi Bhabha e comenta que o hibridismo do texto pós-colonial é fomentado pelas inúmeras traduções culturais que escritores diaspóricos precisam fazer (BOEHMER, 2005, p. 227). Em Americanah, o estilo híbrido se harmoniza com a temática do romance e com a abordagem de experiências múltiplas que afetam subjetividades diaspóricas. A escolha de criar uma protagonista blogueira também condiz com o contexto contemporâneo do romance e com o posicionamento da autora. O engajamento político-social de Adichie é bastante conhecido para além de sua ficção, desde a sua primeira conferência TEDx, "The Danger of a Single Story" (2009) e através de diversos vídeos disponíveis on-line.

Nas aulas de graduação e no contexto apropriado tenho por hábito fazer referências às escritoras/obras contemporâneas de expressão inglesa que fazem parte da minha pesquisa. No caso de Adichie, em contraste com outras escritoras mais estabelecidas no meio literário, vários/as alunos/as demonstram familiaridade com a escritora e suas publicações on-line. Na palestra que a tornou conhecida, Adichie relata incidentes que funcionam como uma contra-narrativa da história única difundida no ocidente sobre a África, desconstruindo a visão distorcida do continente enquanto país. Rechaça, também, com humor, a ideia de que o comportamento violento do patriarca de seu primeiro romance, Purple Hibiscus (2004), seja representativo do homem nigeriano. Adichie adverte contra o "perigo da história única", inevitavelmente calcada em estereótipos que, de acordo com ela, mesmo não sendo inteiramente falsos, são incompletos e transformam uma história na única história. Enfatiza também a associação entre a criação de estereótipos e as 
redes mundiais de poder. "Como as histórias são contadas, por quem são contadas, quando são contadas, quantas histórias são contadas" (TEDx, 2009) - todas são variantes atreladas à questão de poder. O poder de alcance da palestra e o estilo accessível (por que não mencionar didático?) de Adichie dão visibilidade, entre outras questões, à conexão entre a fixidez de estereótipos e a sedimentação do racismo.

Em sua segunda conferência TEDx (2015), que tem como título (convidativo ou provocativo?) "We should all be feminists", Adichie também aborda estereótipos, mas desta vez privilegia questões de gênero. A partir de uma recordação antiga - a primeira vez em que foi chamada de feminista, palavra cujo significado desconhecia, mas que certamente não soava como elogio - ela narra vários incidentes ao longo dos anos nos quais noções estereotipadas e conotações negativas associadas à palavra eram o elemento constante. Os incidentes reforçam a convicção de Adichie de que tanto a palavra "feminista" como a própria ideia de feminismo é limitada por estereótipos. Fala da sua raiva das injustiças cometidas em nome das diferenças de gênero e da sua esperança no potencial dos seres humanos de criar um mundo melhor, no qual meninos e meninas não sejam mais educados de acordo com padrões sexistas. À guisa de conclusão, retorna à primeira vez em que foi chamada de feminista e à definição que encontrou no dicionário: "uma pessoa que acredita em igualdade social, política e econômica entre os sexos". Conta que sua bisavó não conheceu a palavra, mas que certamente agiu como uma feminista e termina com sua definição própria. "A meu ver, feminista é o homem ou a mulher que diz: Sim, existe um problema de gênero ainda hoje e temos que resolvê-lo, temos que melhorar. Todos nós, mulheres e homens, temos que melhorar" (2015). A conferência (também disponível em formato de livro) conta com mais de quatro milhões de visualizações, incluindo a da cantora Beyoncé, que inseriu parte do discurso com a voz de Adichie (sem autorização prévia) em "Blessed", uma de suas músicas. Sem dúvida, "We should all be feminists" viralizou, o que é extremamente positivo, mas não significa o fim de diferenças, divergências e controvérsias sobre o termo. ${ }^{3}$

Ainda que parte da crítica especializada considere que a literatura pós-colonial é escrita por uma elite que vive nos centros hegemônicos, e que interesses políticos e mercadológicos, aliados à atração pelo exótico, ditem a circulação e popularidade dessa literatura - questões que inegavelmente precisam ser pensadas -, adotar um rótulo único para uma produção tão diversa me parece uma posição reducionista. Além de sua produção literária, o poder de alcance das duas palestras e de inúmeras publicações on-line; o estilo accessível, incisivo, por vezes didático; e a ironia sutil que caracteriza os textos não ficcionais de Adichie são diversos fatores que confirmam seu engajamento político. Ao mesmo tempo, contribuem para dar visibilidade à conexão entre a fixidez de estereótipos e a sedimentação do racismo e do sexismo, ampliando a discussão sobre os feminismos na contemporaneidade.

Sem sombra de dúvida, o status e visibilidade de Chimamanda Adichie estão diretamente ligados à questão levantada por Ângela Davis a respeito da facilidade com que ideias circulam a partir dos Estados Unidos. No entanto, como Davis sugere, produção e circulação de conhecimento nem sempre ocorrem simultaneamente. Práticas e estéticas políticas adotadas por mulheres que ocupam lugares sociais e geográficos fora das redes de poder e conhecimento dos centros hegemônicos contribuem para ampliar o diálogo sobre os feminismos atuais, desconstruir estereótipos e promover a descolonização de gênero. Focalizo aqui o funk de Mc Carol, o teatro do Coletivo Madalena Anastácia e o slam de Luz Ribeiro, artistas negras brasileiras, que, através de linguagens variadas, "descortinam possibilidades de novos agenciamentos políticos e de construção de epistemologias heterodoxas e não hegemônicas" (MACEDO; SCHMIDT, 2017).

A funkeira Carolina de Oliveira Lourenço cresceu em Niterói, na periferia, e aprendeu muito cedo a importância de conquistar seu espaço. A pele negra e o desconhecimento da palavra feminista enquanto crescia são dois pontos em comum com Chimamanda Adichie. Conversando com Helô D'ANGELO (2016), Mc Carol afirma:

"Feminista" é um rótulo que eu só conheci no ano passado, mas sempre tive na cabeça que deveria existir igualdade entre todas as pessoas. Sempre lutei por isso, desde pequena. É como uma armadura, uma proteção, a única forma que eu encontrei de eu conseguir respeito, me colocando como igual aos homens. Eu sempre tive muita autoridade lá no morro. Levava porrada na rua, mas também batia.

Hoje, ainda não sei totalmente o que é ser feminista, mas estou desvendando, de pouquinho em pouquinho. Depois de ler bastante e de conversar muito, sei que o vulgo feminista é a mulher que luta pelos seus direitos. E aí pensei: sempre fui essa mulher.

As declarações de Mc Carol e trechos de suas composições mostram que seu saber está ligado a experiências de vida ("teorizando na carne", como diz Cherríe Moraga) que precedem

\footnotetext{
3 "Dear ijeawele, or a feminist manifesto in fifteen suggestions", postado no Facebook em dezembro de 2016 (https:/ /www.facebook.com/chimamandaadichie/posts/101544127084) e publicado no ano seguinte, dá continuidade à discussão sobre feminismo, que Adichie afirma, varia de acordo com o contexto.
} 
sua introdução a conceitos como opressão machista, por exemplo. Na primeira estrofe de "100\% Feminista", de 2016 (composta em parceria com Karol Conka), a voz carrega a força do testemunho, das memórias de infância, e da determinação de quebrar os ciclos de submissão e violência:

Presenciei tudo isso dentro da minha família/ Mulher com olho roxo, espancada todo dia Eu tinha uns cinco anos, mas já entendia Que mulher apanha se não fizer comida Mulher oprimida, sem voz, obediente Quando eu crescer, eu vou ser diferente.

O crítico musical Leonardo Lichote (In: Luccas OLIVEIRA, 2016) comenta o resultado da parceria de Mc Carol (funk) e Karol Conka (rap) em "100\% Feminista" e ressalta que a diferença de perspectiva do feminismo das duas artistas está inscrita em seus respectivos versos: "Enquanto Carol coloca a dureza clara da experiência pessoal [...], Karol expõe um olhar mais analítico ("Século XXI/ E ainda querem nos limitar/ Com novas leis") - uma alimentando e fortalecendo a contundência da outra". Ainda que a contundência da letra seja inegável, Lichote ignora o princípio fundamental do feminismo de que "o pessoal é político" (Carol HANISCH, 1969). Na realidade, as perspectivas das duas artistas são analíticas e políticas. Mc Carol foca em um olhar microssocial sobre seu cotidiano enquanto Karol Conka volta seu olhar para o macrossocial.

As performances do Coletivo Madalena Anastácia, do Rio de Janeiro, constituem outra manifestação estética e política de resistência aos padrões impostos pela cultura dominante. $O$ coletivo de mulheres negras ativistas, idealizado por Barbara Santos e atuante desde 2015, integra a Rede Madalena Internacional, composta por grupos feministas da América Latina, Europa e África, que promovem a discussão e a criação de ações concretas pelos direitos das mulheres. $O$ coletivo do Rio de Janeiro usa a arte para discutir e enfrentar os desafios encontrados pelas mulheres negras. A proposta é fazer do teatro das oprimidas uma ferramenta política de transformação social ao expor as articulações entre as opressões de gênero e raça. No IV Encontro Latino Americano del Teatro de los Oprimidos na Nicarágua (2016), o grupo apresentou "Consciência do cabelo aos pés", uma peça de Teatro-Fórum que se caracteriza pelo formato de pergunta, respostas, novas perguntas, possíveis respostas ou caminhos como instrumento de conscientização da plateia. A performance focaliza a estética da mulher negra enquanto estratégia de luta que se contrapõe ao racismo e machismo impostos sobre os seus corpos. "Bela, bela, sensual - todas querem ser igual", refrão do texto dramático em questão sublinha o poder da mídia sobre o corpo negro, "do cabelo aos pés".

Vários teóricos/as, incluindo Stuart Hall, Gayatri Spivak e Sandra Regina Goulart Almeida, observam que o corpo da mulher negra é o corpo mais controlado na diáspora (Sandra Regina Goulart ALMEIDA, 2015, p. 121). São corpos marcados. Não se trata, aqui, de igualar as diferenças e, sim, de entender que a diferença marca, discrimina, controla. O uso do corpo como espaço político, seja através da palavra ou de outras linguagens artísticas, é um ato duplamente transgressor que tem o potencial de quebrar ciclos de submissão, controle e violência. Em trabalho apresentado no Seminário Internacional Fazendo Gênero 11 \& $13^{\text {th }}$ Women's Worlds Congress, Carolina A. F. NETTO (2017), professora, mestranda e atriz do Coletivo Madalena Anastácia, sintetiza sua experiência no grupo e a importância deste trabalho coletivo:

O fazer teatro adquire um sentido que vai além da representação, é carregado de sentidos, de reativações de memória, de releitura de seus próprios corpos, sua disposição no espaço e no mundo. Diante das ferramentas que o Teatro das Oprimidas nos proporciona, é possível operar no modus operandi em outra frequência se possível, leitura de corpos do "outro", leituras de espaços, de entonação de vozes e o que elas pretendem dizer (p. 11).

A força do corpo, mais especificamente da voz, como instrumento político e estético, se faz presente na poesia falada/slam de Luz Ribeiro. Primeira mulher a vencer o Slam BR (Campeonato Brasileiro de Poesia Falada) 2016 e a competir no campeonato internacional na França no ano seguinte, a poeta paulista de vinte e nove anos se autorrepresenta em "Deu(s) Branco": "preta, pobre, proletária/ sabe muito bem o que é ser o capim/ na cadeia alimentar". No entanto, a consciência do seu lugar social e as experiências de exclusão e discriminação desde a infância não são fontes de vitimização. A leitura e a escrita, que fizeram parte do seu cotidiano e de sua família, contribuíram para que Luz construísse um caminho para sua autoafirmação. Formada em educação física e pedagogia, com experiência de trabalho com adolescentes em conflito, desde 2012 começou a participar de saraus e batalhas de poesia. Lançou seu primeiro livro, Eterno Contínuo, em 2013, e vem se firmando como poeta e atriz. Coloca em prática o princípio de coletividade associado ao feminismo negro ao participar de vários grupos, entre eles, o Slam das Treze, Poetas Ambulantes, que lê poesia e distribui livros em transportes públicos, e Legítima Defesa. Tem consciência do seu lugar social e do seu papel como poeta. 
Escrevo do lugar onde estou. Sou mulher, negra, nascida em lugar pobre. Eu gostaria de falar mais sobre o mar, sobre a natureza, sobre as pessoas que nascem. Mas o que é mais urgente pra mim são as pessoas que estão morrendo. E esse sangue tem cor. Mais importante pra mim é falar sobre como as mulheres ainda são sujeitas à invisibilidade. A poesia é minha arma de revide. E esse é meu tempo. Não posso deixar que ele passe (Fernanda MIRANDA, 2017).

Em suas falas e seus poemas fica evidente que conquistar um lugar de fala implica conquistar um lugar para ser ouvida, e realizar o "sonho de não ser invisível" (SLAM, 2017).

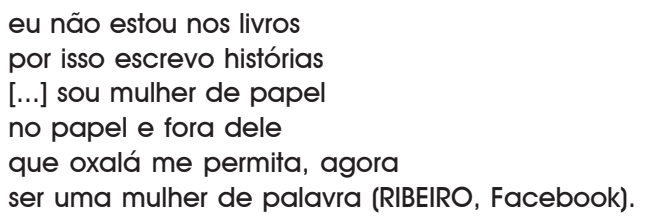

A produção artística/ cultural de Mc Carol, do Coletivo Madalena Anastácia e de Luz Ribeiro são apenas algumas das muitas histórias que estão sendo contadas. São poéticas de resistência e descolonização de gênero que, construídas em suas diferenças, integram os feminismos na contemporaneidade. Estas artistas se autorrepresentam, falam por si mesmas. Em um de seus poemas, Luz Ribeiro desabafa: "já fizemos muitos minutos de silêncio/ agora serão gerações e gerações de barulho" (In: CORRESPONDÊNCIA POÉTICA). É preciso ouvir atentamente.

\section{Referências}

ADICHIE, Chimamanda Ngozi. Purple Hibiscus. New York: Random House Inc., 2004.

ADICHIE, Chimamanda Ngozi. Americanah. New York: Anchor Books, 2013.

ADICHIE, Chimamanda Ngozi. "We should all be feminists", 16/11/2015. Disponível em: http:// singjupost.com/we-should-all-be-feminists-by-chimamanda-ngozi-adichie-full-transcript/3/.

ALMEIDA, Sandra Regina Goulart. Cartografias contemporâneas: espaço, corpo, escrita. Rio de Janeiro: 7 Letras, 2015.

BOEHMER, Elleke. Colonial and Postcolonial Literature. New York: Oxford University Press, 2005.

COLETIVO MADALENA ANASTÁCIA. Consciência do cabelo aos pés. In: IV ENCONTRO LATINO AMERICANO DEL TEATRO DE LOS OPRIMIDOS NA NICARÁGUA, Nicarágua, 2016. Disponível em: https:/ /www.youtube.com/watch?v=OlU83hdwmBc.

CRENSHAW, Kimberlé. "Documento para o encontro de especialistas em aspectos da discriminação racial relativos ao gênero". Revista Estudos Feministas, p. 176-188, 2002. Disponível em: http:// www.scielo.br/pdf/ref/v10n1/1 1636.pdf. Acesso em 06/08/2016.

D’ANGELO, Helô. "Mc Carol: eu nasci feminista". Revista Fórum, 2016. Disponível em: https:// www.revistaforum.com.br/semanal/mc-carol-eu-nasci-feministal/. (Entrevista concedida por Mc Carol)

DAVIS, Angela. Crossing time and building the future of the fight against racism. Salvador, 25/07/ 2017. Disponível em: https://www.youtube.com/watch?v=2vYZ4IJtgDO.

FRIEDMAN, Susan Stanford. Mappings: Feminism and the Cultural Geographies of Encounter. Princeton: Princeton University Press, 1998.

GUARRACINO, Serena. "Writing 'so raw and true'": Blogging in Chimamanda Ngozi Adichie's Americanah". Between, v. IV, n. 8, p. 1-27, nov. 2014. Disponível em: http://ojs.unica.it/index.php/ between/article/view/1320. Acesso em 09/2016.

HANISCH, Carol. O pessoal é político. Disponível em: https://resistenciaradfem.wordpress.com/tag/ carol-hanisch/. Acesso em 02/07/2018.

MACEDO, Ana Gabriela; SCHMIDT, Simone Pereira. Simpósio Temático "Feminismos Transnacionais: saberes e estéticas pós/descoloniais". In: FAZENDO GÊNERO 11. Florianópolis, UFSC, 2017.

Mc CAROL; CONKA, Karol. "100\% Feminista”. Vagalume, 2016. Disponível em: https:// www.vagalume.com.br/mc-carol/100-feminista.html. 
MARTIN, Michel. Feminism is fashionable for nigerian writer Chimamanda Ngozi Adichie, 18/03/ 2014. Disponível em: http://www.npr.org/templates/transcript/transcript.php?storyld=291133080. (Entrevista concedida por Chimamanda Ngozi Adichie)

MIRANDA, Fernanda. "Campeã nacional de poesia é mulher, negra e nascida na periferia", Catraca Livre, 17/03/2017. Disponível em: https://catracalivre.com.br/cidadania/campea-nacional-depoesia-e-mulher-negra-e-nascida-na-periferia/.

NETTO, Carolina A. F. "Madalena Anastácia: uma investigação cênica de mulheres negras no teatro das oprimidas". In: SEMINÁRIO INTERNACIONAL FAZENDO GÊNERO 11 \& $13^{\text {th }}$ WOMEN'S WORLDS CONGRESS. Anais Eletrônicos, Florianópolis, 2017, p. 1-12. Disponível em: http://www.wwc2017. eventos.dype.com.br/resources/anais/1499404155_ARQUIVO_ArtigoMadalenaAnastacia.pdf

OLIVEIRA, Luccas. "MC Carol une forças com Karol Conka para falar de feminismo em single". O Globo, 06/10/2016. Disponível em: https://oglobo.globo.com/cultura/musica/mc-carol-une-forcascom-karol-conka-para-falar-de-feminismo-em-single-20246078\#ixzz59I2zj5Te.

RIBEIRO, Luz. "Deu(s) Branco”. M de Mulher, 14/03/2017. Disponível em https://www.youtube.com/ watch?v=Eb9odWlvVyl.

RIBEIRO, Luz. Ełerno contínuo. São Paulo: Quirino, 2013.

RIBEIRO, Luz. "Mulher de Palavra”. Facebook. Disponível em: https://www.facebook.com/ luzribeiropoesia/videos/1338801549482900/.

RIBEIRO, Luz. "Gerações de Barulho". Correspondência poética. Disponível em: http:// www.correspondenciapoetica.com.br/festival/ii-festival-de-poesia/396-geracoes-de-barulho.

SLAM: a resistência poética e invisibilidade, com Luz Ribeiro / Prazer, eu sou!, 08/08/2017. Disponível em: https://www.youtube.com/watch?v=XYug6v_3SwY. Volpato

SCHMIDT, Simone Pereira. "Sexo, raça e gênero na lógica colonial: o que contam as mulheres". In: ZINANI, Cecil Jeanine Albert; SANTOS, Salete Rosa Pezzi (org.). Trajetórias de literatura e gênero: territórios reinventados. Caxias do Sul: EDUCS, 2016. p. 13-24.

SHOHAT, Ella. "Estudos de área, estudos de gênero e as cartografias do conhecimento". In: COSTA, Claudia de Lima; SCHMIDT, Simone Pereira (org.). Poéticas e políticas feministas. Ilha de Santa Catarina: Mulheres, 2004. p. 19-29.

TEDx. Ideas worth spreading. The Danger of a Single Story, 07/10/2009. Disponível em: http:// www.ted.com/talks/chimamanda_adichie_the_danger_of_a_single_story.html. (Pronunciamento de Chimamanda Ngozi Adichie)

TUNCA, Daria. Interview, 27/01/2005. Disponível em http://www.cerep.ulg.ac.be/adichie/ cnainterview.html. (Entrevista concedida por Chimamanda Ngozi Adichie)

Leila Assumpção Harris (iD) 0000-0002-9408-7041

Doutora em Inglês (Literatura Norte-Americana) pela Texas Tech University

É Professora Associada da Universidade do Estado do Rio de Janeiro e bolsista FAPERJ (Procientista). Na graduação, atua no setor de Literatura Norte-Americana e, na Pós-Graduação, em Estudos Literários, na Especialidade de Literaturas de Língua Inglesa. Tem experiência na área de Letras, com ênfase nas literaturas de língua inglesa, literatura comparada, literaturas contemporâneas de autoria feminina, estudos de gênero, classe e etnia, estudos culturais. É líder do grupo de pesquisa do CNPq A voz e o olhar do Outro: questões de gênero e/ou etnia nas literaturas de língua inglesa.

Universidade do Estado do Rio de Janeiro, Pós-Graduação em Letras da UERJ, Departamento de Letras Anglo-Germânicas, Instituto de Letras

Rua São Francisco Xavier 524, $11^{\circ}$ andar

20550-900 - Rio de Janeiro - RJ - Brasil

secretaria-pgletras@yahoo.com.br

harris.leila@gmail.com 


\section{COMO CITAR ESSE ARTIGO DE ACORDO COM AS NORMAS DA REVISTA}

HARRIS, Leila Assumpção. "Desvelando afinidades através das diferenças: saberes e estéticas pós/descoloniais". Revista Estudos Feministas, Florianópolis, v. 27, n. 1, e58973, 2019.

\section{CONTRIBUIÇÃO DE AUTORIA}

Não se aplica

\section{FINANCIAMENTO}

Prociência (FAPERJ)

\section{CONSENTIMENTO DE USO DE IMAGEM}

Não se aplica

\section{APROVAÇÃO DE COMITÊ DE ÉTICA EM PESQUISA}

Não se aplica

\section{CONFLITO DE INTERESSES}

Não se aplica

\section{LICENÇA DE USO}

Este artigo está licenciado sob a Licença Creative Commons CC-BY. Com essa licença você pode compartilhar, adaptar, criar para qualquer fim, desde que atribua a autoria da obra.

\section{HISTÓRICO}

Recebido em 02/09/2018

Aprovado em 07/09/2018 